\title{
Spatial probability modelling of forest productivity indicator in Italy
}

\author{
Nazzareno Diodato ${ }^{\mathrm{a}}$, Gianni Bellocchi ${ }^{\mathrm{a}, \mathrm{b}, *}$ \\ ${ }^{a}$ Met European Research Observatory, International Affiliates Program of the University Corporation for Atmospheric Research, 82100 Benevento, Italy \\ ${ }^{\mathrm{b}}$ UCA, INRA, VetAgro Sup, Unité Mixte de Recherche sur l'Écosystème Prairial (UREP), 63000 Clermont-Ferrand, France
}

\section{A R T I C L E I N F O}

\section{Keywords:}

Forest productivity

Geostatistical modelling

Spatial patterns

\begin{abstract}
A B S T R A C T
The prediction of forest productivity is essential for sustainable forest management, particularly in countries, like Italy, where forest is an important part of many protected areas.

A spatial predictive probability model for forest productivity rates in Italy was developed over the period 1961-1990, based on 135 annually-resolved records of site productivity and auxiliary variables measured at 219 stations. Our analysis shows that the probability of finding high $\left(>7.3 \mathrm{~m}^{3} \mathrm{ha}^{-1} \mathrm{yr}^{-1}\right)$ and low $\left(<5.8 \mathrm{~m}^{3} \mathrm{ha}^{-1} \mathrm{yr}^{-1}\right.$ ) productivity rates changes across different regions of Italy. The generated spatial patterns contribute to a better understanding of the factors structuring the distribution of forest productivity in Italy because they reflect the dependence of temperature and water availability conditions on the latitudinal and altitudinal location of the study areas. We observed that the temperature control dominates forest productivity at high elevations and latitudes, whereas low-elevation sites in central and southern Italy are more sensitive to water availability. The proposed spatial probability modelling should be further assessed for its possible incorporation into forest management plans.
\end{abstract}

\section{Introduction}

The spatial extent and pattern of wood distribution have a great influence on the microclimate, pedogenesis and hydrology, including soil erosion of both aquatic and terrestrial ecosystems (Diodato and Bellocchi, 2008b; Diodato et al., 2017), linking up to regional and global climatic aspects (Gaillard et al., 2018; Morin et al., 2018).

In recent decades, Earth scientists have become increasingly interested in the spatial patterns of ecological processes, including the environmental factors that govern forest productivity (Ollinger et al., 1998; Purves and Pacala, 2008; Rahman et al., 2015; Forzieri et al., 2017). The analysis of complex interactions between spatial distribution patterns of site factors and woody vegetation growing is crucial for understanding the functioning of terrestrial ecosystems, as well as their management and planning challenges (Hörsch, 2003). Accurate estimation of forest productivity requires understanding of the topo-climatic drivers of forest productivity patterns (Stegen et al., 2011), which in turn depend on ecological conditions and geographic location (Babst et al., 2013; Martinez del Castillo et al., 2018).

The analysis of forest productivity patterns in complex areas is challenging, mostly because the complex topography and soil diversity of certain regions may cause considerable variations in site-specific responses but also because of the sparsity of available bio-climatic information that is required to estimate productivity (Benavides et al., 2009). Forest biomass estimations may be needed at unsampled locations in a region, for which a procedure is required for mapping forest productivity. In countries with diverse geographical and climatic conditions like Italy (the focus of this study), detailed mapping of all areas is practically and economically difficult. In Italy, with about $90000 \mathrm{~km}^{2}$, forests are estimated to cover about one third of the national territory, and the enhancement of high-nature value forestry environments is a strategic objective of the European Rural Development Policy (Pignatti et al., 2012). The Italian National Forest Inventory (https://www.inventarioforestale.org) provides, at country and regional levels, high-resolution estimates of the increase in volume of the trees measured at the time of the survey. At the level of smaller administrative units (including associations of municipalities, which are typical of mountain regions), increment data are generally not available, or they are only fragmentarily available (Gasparini et al., 2017). Moreover, simply mapping forest productivity does not capture the drivers of forest productivity or give managers the knowledge they need about productivity-environment relationships (e.g. Bontemps and Bouriaud, 2014). Aerial photography is an advanced method for mapping and monitoring, but it is often hampered by observation noise when conditions are cloudy (Coops, 2015). In fact, only a few applications in Italy have been reported, limited to some sites (e.g. Maselli

\footnotetext{
* Corresponding author.

E-mail address: gianni.bellocchi@inra.fr (G. Bellocchi).
} 
et al., 2006; Laurin et al., 2018).

Simulation modelling in forest productivity can be a practical and effective methodology for studying spatial patterns of forest dynamics and production in relation with topographic and climatic factors (e.g. Goreaud et al., 1999; Kim et al., 2017). Modelling approaches include the use of geographical information systems (GIS) and spatial analysis techniques for estimating forest productivity and searching for sensitive areas that should be devoted to careful timber management practices (e.g. Næsset, 1997; Payn et al., 1999; Busch, 2012; Calvert et al., 2013; Thiffault et al., 2014). In this study, an Italian-wide geospatial modelling was performed to map forest productivity rates (FPR) over a 30year climate period (1961-1990), based on an extensive network of sample points with information about vegetation and topo-climatic factors. The FPR index was designed to indicate the growth potential of plants based on climate factors only, through which high values mean the occurrence of favourable growing conditions. A network of 135 stations providing meteorological and productivity data for the calculation of FPR (based on Paterson, 1956, with revisions by Serrada, 1976) was combined with auxiliary precipitation and elevation data extending over 219 stations (including the first 135 stations), being used as input data in a geostatistical analysis of FPR. With the aim of assessing important factors limiting the spatial distribution of forests, an integrated geostatistics approach was implemented incorporating multiple input datasets (coverage, shape files, raster, grids), which were processed to estimate forest productivity at unsampled locations. Based on the distance between data and data estimation locations, and the description of their spatial configuration and spatial structure by a theoretical semivariogram under the assumption of isotropy (i.e. all directions are equal), our objective was to model spatial patterns of forest productivity, whilst also assessing the uncertainty associated with predicted patterns.

\section{Materials and methods}

\subsection{Study area and data collection}

Italy is a Southern European country characterized by a mixture of topographic systems (peninsular shape, islands, mountain chains, valleys and plains). Centrally located in the Mediterranean Sea basin (Fig. 1a), it is an area through which humid air enters generating precipitation with complex shape, location and evolution of the pressure systems in the atmosphere (Lionello et al., 2006). Influences of the Mediterranean climate on vegetation is evident on the Italian coasts and, becoming more attenuated on the pre-Alpine chains and the Apennines (Combourieu-Nebout et al., 2015).

Along the Apennines chain, changes from a low to a high altitude produce a rapid transition towards cooler and less arid summers, while a gradient of increasing continentality (colder winters and hotter summers, with more pronounced temperature variations) can be found when moving inward the Alps. The continental thermal regime is more likely in Northern parts of the peninsula (e.g. in the Po Valley), which are partly isolated by the Apennines chain. Such heterogeneity is reflected in geographically varied vegetation patterns (Fig. 1b).

The selected stations at which FPR values (135) were estimated, and the set of stations (219) providing auxiliary precipitation and elevation data (Fig. 2a, orange and black dots, respectively), cover different biogeographical regions and climatic settings (Fig. 2b). The number of stations is lower in the islands (Sicily and Sardinia) than in the mainland where, as evidenced by Voronoi (1908) tessellation (notshown), stations are uniformly distributed. Basic climate data for the estimation of forest productivity (Fig. 2a, orange sites) were provided by Food Agricultural Organization (FAO)-database LocClim (FAO, 2014) for the World Meteorological Organization's climate normal period 1961-1990 (for which these data are freely available). The station-specific climatic dataset used in the analysis was built upon monthly climatological data, which were directly extracted from the FAO database. Yearly values were derived from monthly ones.

Data were available at 135 stations for all the variables needed for model application. However, the ability to identify the true spatial variability of a dataset depends, to a great extent, on ancillary knowledge of the underlying measured phenomenon (Diodato and Bellocchi, 2008a). Auxiliary precipitation, temperature and elevation data were derived from the Hydrological Annals of the Italian Hydrographic and Oceanographic Service (SIMN), which covered 219 stations equipped with operational rain gauges (accessible on-line - http://www. isprambiente.gov.it/it/progetti/acque-interne-e-marino-costiere-1/ progetto-annali/gli-annali-idrologici - and described by Acquaotta et al., 2016). Weather data included monthly rainfall totals and mean temperatures, and the mean maximum and minimum temperatures of the warmest and the coolest months, respectively. In addition, sunshine durations and growth periods were retrieved from this database.

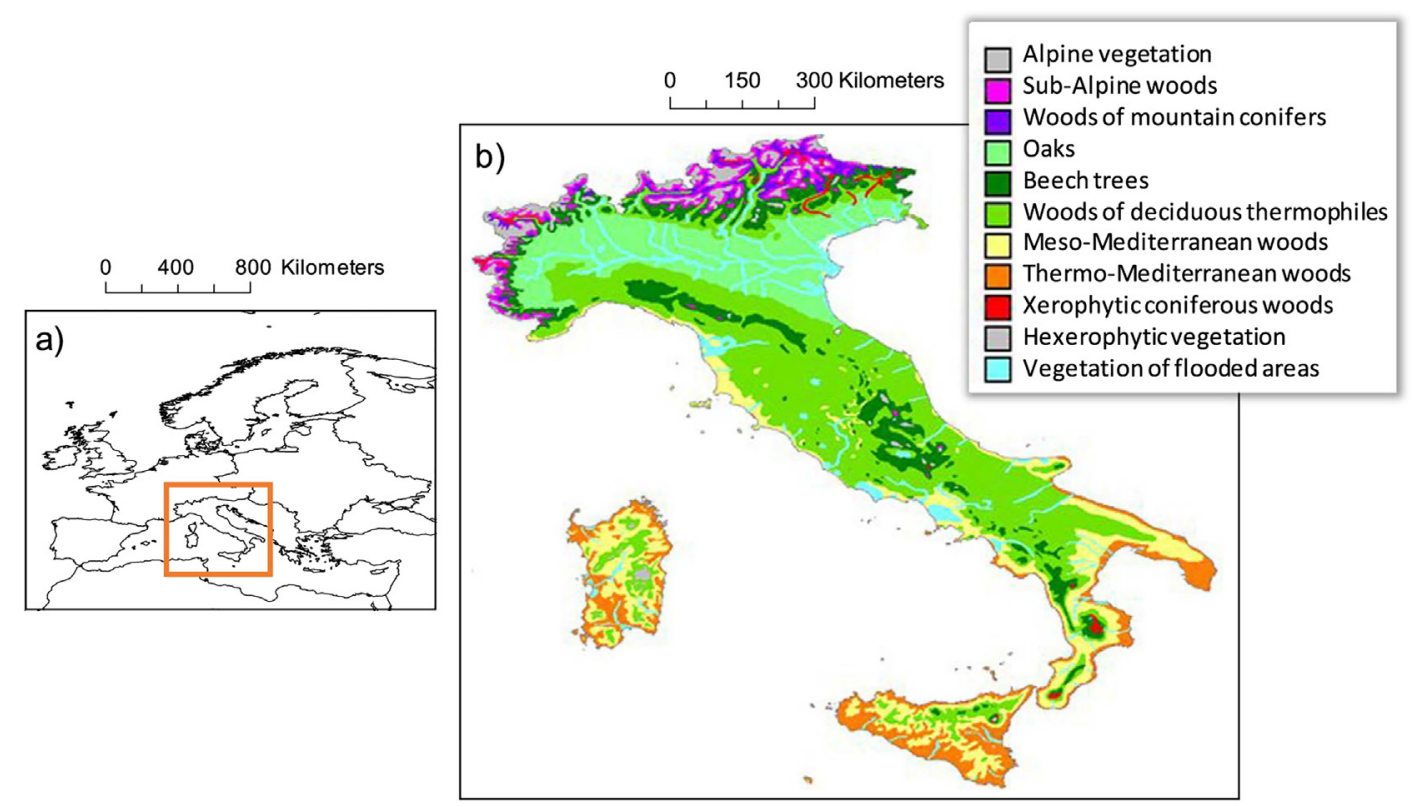

Fig. 1. Environmental settings of the study area (a), and map of potential vegetation of Italy (b), as derived from the European vegetation chart by Bohn et al. (2005). 

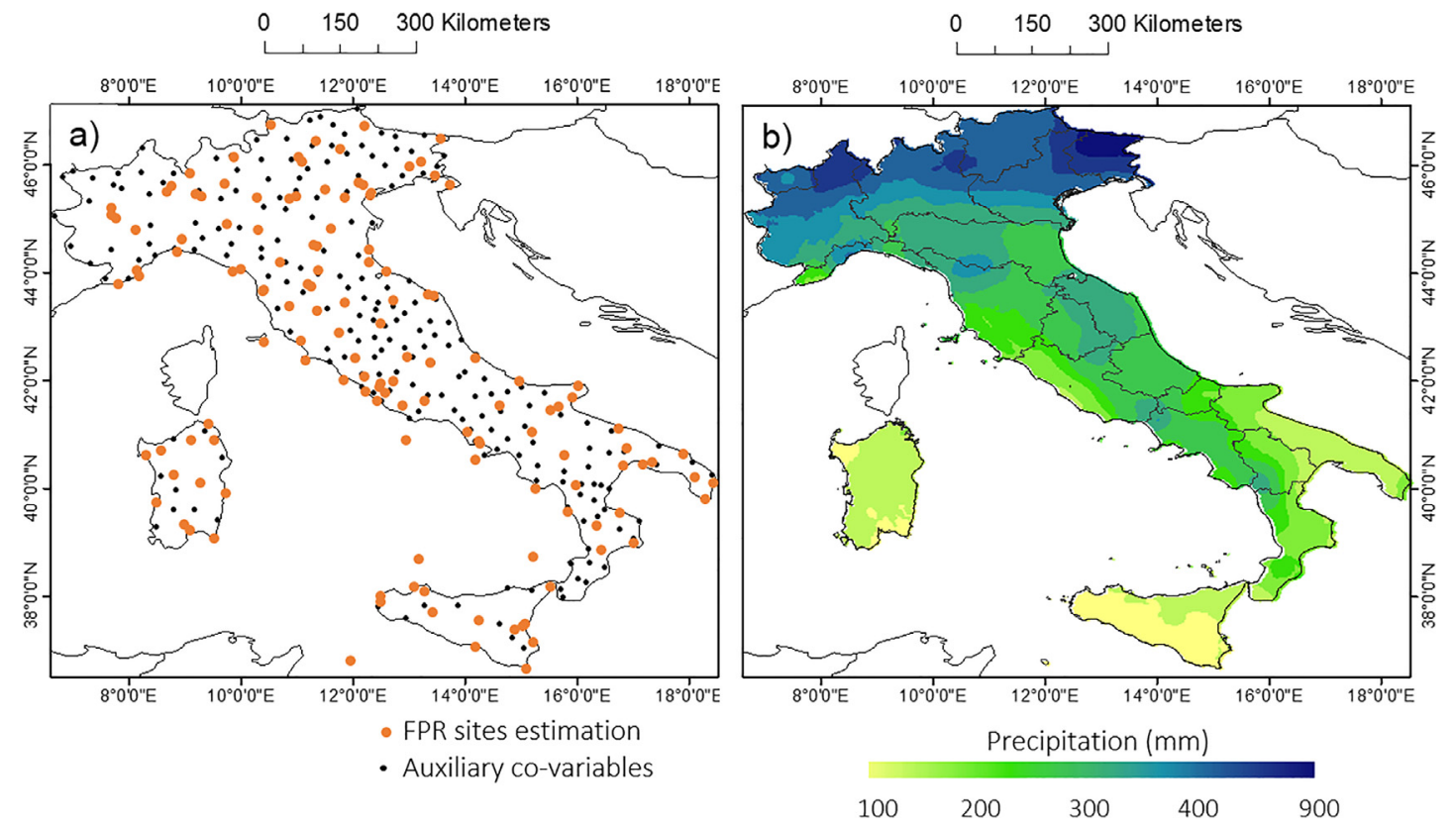

Fig. 2. Geographic distribution of 135 Italian sites for which the FPR (forest productivity rate) was estimated (orange dots), and 219 stations providing auxiliary precipitation co-variables (black points) (a), and spatial patterns of precipitation during the forest growing season (April-September) (b).

\subsection{Long-term forest productivity rate}

According to Paterson (1956), the potential productivity of a forest site is mostly controlled by climate-related factors. They include the flux of solar radiation reaching the ground, the amount of water available for life processes and the time during which thermal resources are favourable to growth (Rahman and Akter, 2015). At a global scale, temperature conditions and water availability appear to be the main controlling factors of forest productivity beyond solar radiation (Churkina and Running, 1998; Wang et al., 2003). A measure of longterm climate-induced site productivity, the FPR index $\left(\mathrm{m}^{3} \mathrm{ha}^{-1} \mathrm{yr}^{-1}\right)$, was derived from concepts by Paterson (1956) and Serrada (1976), as follows:

$F P R=5.2 \cdot \log \left(\frac{P \bullet T_{m(h)} \cdot G \cdot f}{\Delta T \cdot 12}\right)-7.25$

where $P$ is the annual rainfall total $\left(\mathrm{mm} \mathrm{yr}^{-1}\right) ; T_{m(h)}$ is the mean monthly temperature of the hottest month $\left({ }^{\circ} \mathrm{C}\right)$; $G$ is the length of the growing season, here calculated using the latitude (Lat, degrees), the longitude (Long, degrees), the temperature $\left(T_{m(h)}\right.$ as in Eq. (1)) and the elevation (Ele, $\mathrm{m}$ a.s.l.) of the study site:

$G=0.03708 \cdot$ Long $+0.0927 \cdot$ Lat $-0.2781 \cdot T_{m(h)}+0.000927 \cdot$ Ele +4.7

Compared to the conventional number of months with values of De Martonne's aridity index $>20[=p /(t+10)$, where $p$ is monthly precipitation total in $\mathrm{mm}$ and $t$ is monthly average temperature in ${ }^{\circ} \mathrm{C}$; De Martonne, 1926], Eq. (2) takes into account winter seasons (during which low temperatures are the main limiting factor for vegetation growth) and site-specific topographic characteristics.

The reported coefficients of Eq. (2) were determined from a multivariate regression $\left(R^{2}=0.89\right.$ ), performed at 14 stations (covering an altitudinal range from 100 to $2000 \mathrm{~m}$ a.s.l., and located between 8.6 and $16.6{ }^{\circ} \mathrm{E}$ and 39 to $46^{\circ} \mathrm{N}$ ), for which the actual values of the dependent variable $G$ were known (FAO-LocClim). The actual mean value of $G$ is equal to 4 months ( \pm 1 standard deviation), with minimum and maximum values of 2 and 7 months, respectively. The above equation reflects situations frequently occurring in the Mediterranean region, with hot months generally being associated with water limitations, negatively affecting forest growth and productivity when situations of intense and prolonged droughts occur (Lindner et al., 2010). Forest growing seasons logically tend to become longer with increasing latitudes and longitudes, in agreement with more unlikely drought anomalies in the northern regions and towards eastern-central Italy (Fig. 2b). With respect to site elevation, Qiu et al. (2013) found a positive relationship with the length of growing season up to $1500 \mathrm{~m}$ a.s.1., that is, over an altitudinal gradient in which forest productivity is mostly driven by water availability. For elevations above $1500 \mathrm{~m}$ a.s.l., where low temperatures become the most prominent limiting factor, $G$ was set equal to two months, that is, the minimum length of forest growing season (Rahman and Akter, 2015).

The factor $f$ in Eq. (1) is the evapotranspiration reducer suggested by Paterson (1956), calculated by relating the solar radiation at the poles to the radiation at the site of interest. While this is meaningful for differentiating potential plant productivity on a global scale (as originally intended by Paterson), the modified factor $f$ introduced by Gandullo and Serrada (1977) better reflects the relatively small spatial scope of the present study. In this formulation, $f$ considers the real insolation at each site by using the annual number of sunshine hours $\left(n_{\text {sun }}\right)$, as derived from LocClim FAO (2014) database:

$f=\frac{2500}{\left(n_{\text {sun }}+1000\right)}$

In this study, the values of $f$ fluctuated between 0.58 and 1.10, representing a number of sunshine hours of 1270 and $3285 \mathrm{~h}$ per year, respectively; $\Delta T$ is the difference between the mean maximum temperature of the warmest month and the mean minimum temperature of the coolest month $\left({ }^{\circ} \mathrm{C}\right)$. The FPR was calculated for the whole of the Italian territory using data from 135 main stations and auxiliary variables from 219 stations, and interpolation procedures for the creation of continued surfaces.

\subsection{The geostatistical approach for assessing FPR spatial uncertainty}

Geostatistical techniques consider that near spatial data values are more related to each other than distant data values (after Tobler, 1970). The ordinary kriging, in particular, computes an unsampled value (z), knowing its coordinates $(x, y)$ and neighbour values. It makes optimal, unbiased estimates of regionalized variables at unsampled points from 
values of the same variables at surrounding stations, using structural analysis and the initial set of measured data (Journel and Huijbregts, 1978). In the ecological domain, Diodato and Ceccarelli (2004) and Diodato et al. (2010a) used kriging approaches to provide geoindicators to classify soil degradation and assess evapotranspiration rates, respectively. Auxiliary variables can also be used, as in co-kriging (e.g. Knotters et al., 1995). Kriging/co-kriging approaches are probabilistic in nature. They generally return a single value as an estimate at a particular location, but the uncertainty associated with a local estimate can also be calculated, which is useful in decision management (Burrough and McDonnell, 1998). The present analysis targets the latter option by using a type of linear co-kriging, called detrended ordinary co-kriging in the form of probability maps (DOCKpm).

In a first stage, a Detrended Ordinary Co-Kriging with Box-Cox transformation (a power transformation of non-normally distributed data to a set of approximately normal data, after Box and Cox, 1964) was applied to remove the local character of sampled values (Kitanidis, 1997). This was possible because forest growth data were available for more than one attribute per sampled location. In this case, one set of data $\left(Z_{1}=\right.$ forest productivity rate), expensive to measure, was sampled infrequently while another set of data $\left(Z_{2}=\right.$ annual precipitation), cheap to measure, had more frequent observations. Under the assumption that $Z_{1}$ and $Z_{2}$ are spatially correlated, the information about the spatial variation of $Z_{2}$ can be used to map Z1. A co-kriged estimate of the variable of interest at the unsampled location $\mathbf{s}_{\mathrm{o}}$ is given by:

$Z_{1}\left(s_{0}\right)=\lambda_{1} z_{1}+\lambda_{2} z_{2}$

where $\mathbf{z}_{1}$ is a vector of the observed primary data (in this case they correspond to annual forest productivity rates), and $z_{2}$ is a vector of the observed auxiliary variable (in this case they correspond to annual precipitation data) selected in the $\mathbf{s}_{\mathrm{o}}$ neighborhood observation $\mathbf{s}_{\mathbf{j}} ; \boldsymbol{\lambda}_{1}$ and $\lambda_{2}$ are weight vector associated with the distances $h_{\mathrm{o}(\mathrm{i})}$ (between $\mathbf{s}_{\mathrm{o}}$ and $\mathbf{s}_{\mathrm{i}}$ ) and $h_{\mathrm{o}(\mathrm{j})}$ (between $\mathbf{s}_{\mathrm{o}}$ and $\mathbf{s}_{\mathrm{j}}$ ), respectively, and estimated by solving a system of equations (Johnston et al., 2001).

To help mitigate the uncertainties associated with estimates of wood productivity rates, a probabilistic interpretation (probability maps) was given (after Diodato et al., 2013; Diodato and Bosco, 2014). Thus, in a second stage, estimates and their variances were used to calculate and model semivariogram and cross-covariance functions at a range of threshold values $\left(z_{k}\right)$. The semivariogram captures the spatial dependence between samples by plotting semivariance (half the variance of the differences between all possible points spaced a constant distance apart) against separation distance. The cross-covariance gives the covariance of the primary and secondary variables at pairs of points. Both functions quantify the assumption that things nearby tend to be more similar than things that are farther apart. We set $z_{k}$ equal to 5.8 and $7.3 \mathrm{~m}^{3} \mathrm{ha}^{-1} \mathrm{yr}^{-1}$, corresponding to the first and the third quartile of forest productivity values, respectively. In this way, intervals below the lowest threshold and above the highest threshold are captured.

\section{Results}

\subsection{Exploratory data analysis}

Fig. 3a shows the geographical distribution of the trend, which was used for detrending the FPR data. Local environmental conditions (mostly in longitudinal sections) can be recognized as deviations from the global North-South trend. The descriptive statistics of the FPR data show a moderately skewed distribution with a small number of samples with large values (Fig. 3b). The Box-Cox transformation (with parameter equal to 1.6) reduced such skewness towards an approximately normal distribution (Fig. 3c), and then these modified data were used for the DOCKpm.

The estimated mean FPR was equal to $6.37 \pm 1.24 \mathrm{~m}^{3} \mathrm{ha}^{-1} \mathrm{yr}^{-1}$, with values ranging from $2.57 \mathrm{~m}^{3} \mathrm{ha}^{-1} \mathrm{yr}^{-1}$ for the Paganella mountain (46.17 N, $11.07 \mathrm{E}, 2129 \mathrm{~m}$ a.s.1.) to $8.73 \mathrm{~m}^{3} \mathrm{ha}^{-1} \mathrm{yr}^{-1}$ at Udine
(46.07 N, $13.23 \mathrm{E}, 116 \mathrm{~m}$ a.s.l.).

\subsection{Auxiliary information integration}

The observational scale of topo-climatological variables used as auxiliary information is of great importance. In this context, indices are usually designed to represent the main drivers or effects across particular lands where only a minimum set of primary data is available. The direct use of annual precipitation as secondary information produced satisfactory results (correlation coefficient equal to 0.69, Fig. 4a). The cross-covariance modelling with a spherical function (curve in Fig. $4 \mathrm{~b}$ and Eq. (6)), with range of $\sim 80 \mathrm{~km}$ (radius of the black circle in Fig. 4b1), confirms an important positive spatial relationship between primary (FPR) and auxiliary (precipitation) variables as the distance is reduced among sampled station-points.

\subsection{Structural analysis and modelling}

We fitted a theoretical semivariogram to the observed data under the assumption of isotropy, and obtained the cross-covariance function between FPR and precipitation. Empirical semivariogram and crosscovariance are indicated with $\gamma_{11}(\mathbf{h}) C_{12}(\mathbf{h})$, respectively, where subscripts 1 and 2 designate $F P R$ and precipitation data, respectively. Parameters such as range $a(\sim 80 \mathrm{~km})$, number of lags (assumed equal 7) and lag size $\mathrm{h}$ (assumed equal to $40 \mathrm{~km} \approx$ minimum distance among samples) were calibrated iteratively throughout the run. Once verified the assumption of isotropy, the semivariogram was modelled for both the FPR thresholds as a combination of two distinct spatial structures (nugget variance and spherical structure):

$$
\left\{\begin{array}{cc}
3.2665 & \mathbf{h}=0 \\
6.2226 \cdot \operatorname{Shp}(|\mathbf{h}|, a)+3.2665 \cdot N u g g e t & 0<\mathbf{h} \leq a \\
9.4925 & \mathbf{h}>a
\end{array}\right.
$$

while for the cross-covariance functions:

$\left\{\begin{array}{cc}446.09 & \mathbf{h}>a \\ 446.09 \cdot \operatorname{Shp}(|\mathbf{h}|, a) & 0<\mathbf{h} \leq a\end{array}\right.$

where $\operatorname{Shp}(|\mathbf{h}|, a)$ is the spherical correlation function equal to

$\left\{\frac{3}{2}\left(\frac{|\mathrm{h}|}{a}\right)-\frac{1}{2}\left(\frac{|\mathrm{h}|}{a}\right)^{3}\right\}$

The neighbourhood of points was controlled by a search circle describing the isotropic geometry of the neighbourhood, with semi-axis of about 80 and $100 \mathrm{~km}$ limiting the number and the configuration of the points used for prediction. The elements closest to each other tend to be more similar because as the data positions move from a position where the value is unknown, they may not be as useful in predicting the value in an unsampled position. At a certain distance, the points will have no correlation with the position of prediction, and could even be in a very different area than the unknown position.

\subsection{Spatial pattern of probabilities mapping}

Fig. 5 shows the final co-kriged map estimates of FPR for the thresholds of (lower than) 5.7 and (higher than) $7.2 \mathrm{~m}^{3} \mathrm{ha}^{-1} \mathrm{yr}^{-1}$. In particular, Fig. 5a shows the spatial patterns of the probability of lowproductivity areas. These are mostly located in Trentino-Alto Adige (north-east), Umbria and Latium (centre), Apulia and Basilicata (south), and Sicily and southern Sardinia (islands). Fig. 5b illustrates spatial changes of the probability of high-productivity areas, mostly located across Piedmont, Lombardy, Liguria (north-west), Friuli-Venezia Giulia (north-east), Marche and (to a lesser extent), Tuscany (centre), Central and southern Campania, western Basilicata and Calabria (south).

The conclusion is that more suitable areas (that is, with high probability of forest productivity) are located in northern Italy. Instead, 

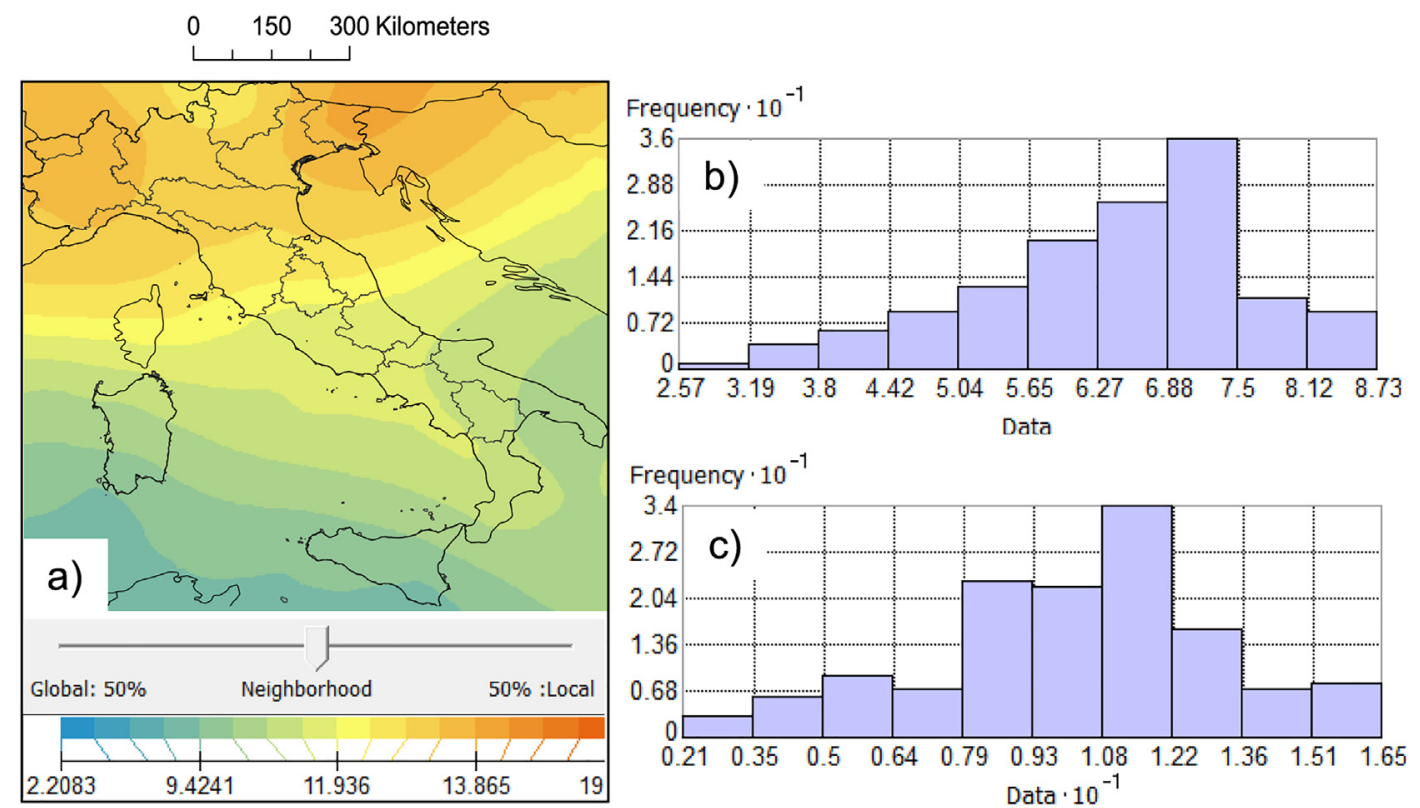

Fig. 3. Geographical trends of forest productivity rates (FPR) (a), statistical distribution of baseline FPR data for the original series over the period 1961-1990 (b), and statistical distribution of baseline FPR data after Box-Cox transformation (c). FPR data are expressed as $\mathrm{m}^{3} \mathrm{ha}^{-1} \mathrm{yr}^{-1}$.

a)

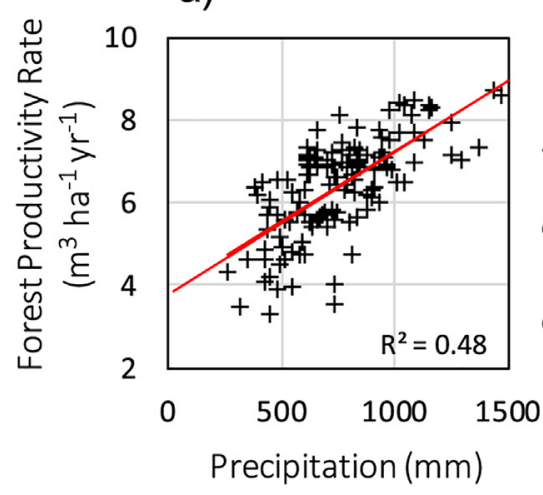

b)

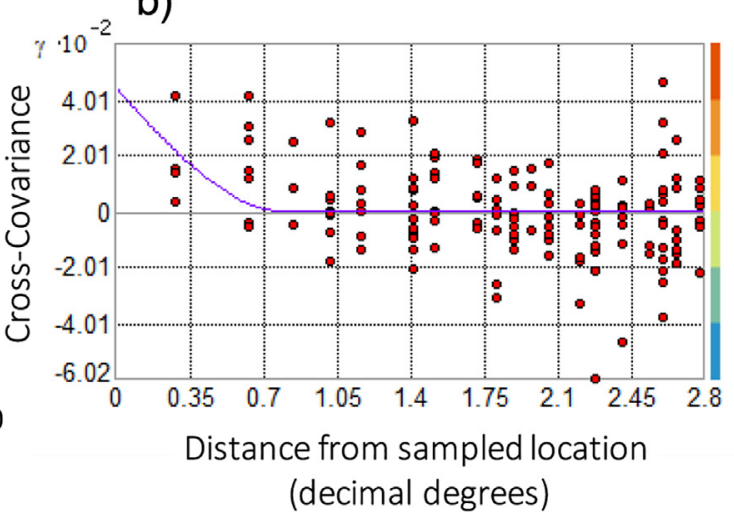

$\left.b_{1}\right)$

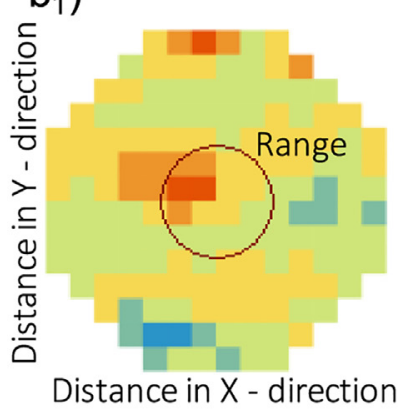

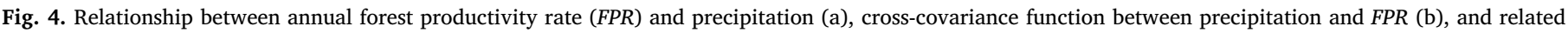

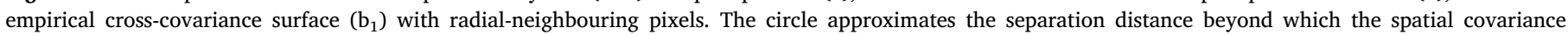

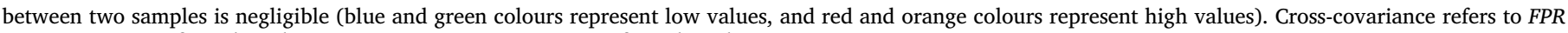
threshold of $7.3 \mathrm{~m}^{3} \mathrm{ha}^{-1} \mathrm{yr}^{-1}$ (results for the threshold of $5.8 \mathrm{~m}^{3} \mathrm{ha}^{-1} \mathrm{yr}^{-1}$ are very similar and not shown here).

Latium, Sardinia, Sicily and Apulia are the regions with high probability to have a poor suitability to forest productivity. In these areas, the scarce precipitation regimes during the growing season, combined with high evapotranspiration rates, cause limited water availability for plants growth.

\subsection{Cross-validation assessment}

The error involved on the expansion of the information from point to landscapes through probability co-kriging estimation at fine grid can be assessed through an estimated indicator's standard error and crossvalidation (Isaaks and Srivastava, 1989). In the cross-validation diagrams (Fig. 6), the actual values of FPR compare well with the predicted probability indicators for both the highest (Fig. 6a) and lowest (Fig. 6b) threshold values. Mean values are -0.002 (for $F P R<$ $5.7 \mathrm{~m}^{3} \mathrm{ha}^{-1} \mathrm{yr}^{-1}$ ) and 0.0249 (for FPR $>7.2 \mathrm{~m}^{3} \mathrm{ha}^{-1} \mathrm{yr}^{-1}$ ), showing lack of systematic errors. Root mean squared error values are 0.420 and 0.400 , respectively.

\section{Discussion}

Detailed studies are necessary to establish the mechanisms underlying unique functional relationships between climate and forest growth in the complex set of physiological processes governing the response of trees to water and temperature stress. This paper presents a geostatistical modelling framework for proper interpretation of spatially-explicit forest productivity rates (FPR) in Italy, which assumes a set of quantitative data for the location of interest (temperature, rainfall, duration of the growth season) and probabilities associated with ranges of productivity above and below critical values. They include the best available data from a set of stations (135) and secondary data from a wider set (219), as provided by the existing FAOclim database. In this way, the use of topo-climate variables as a source of auxiliary information for estimating the FPR for site-specific and other spatial information is an important issue of this paper. Trend analysis has shown the existence of a non-random (deterministic) component in the spatial distribution of data. In particular, the largest gradient of the FPR data occurs along the northwest to southeast direction (Fig. 3a), which can be attributed to Atlantic influences determining more persistent rainfall 

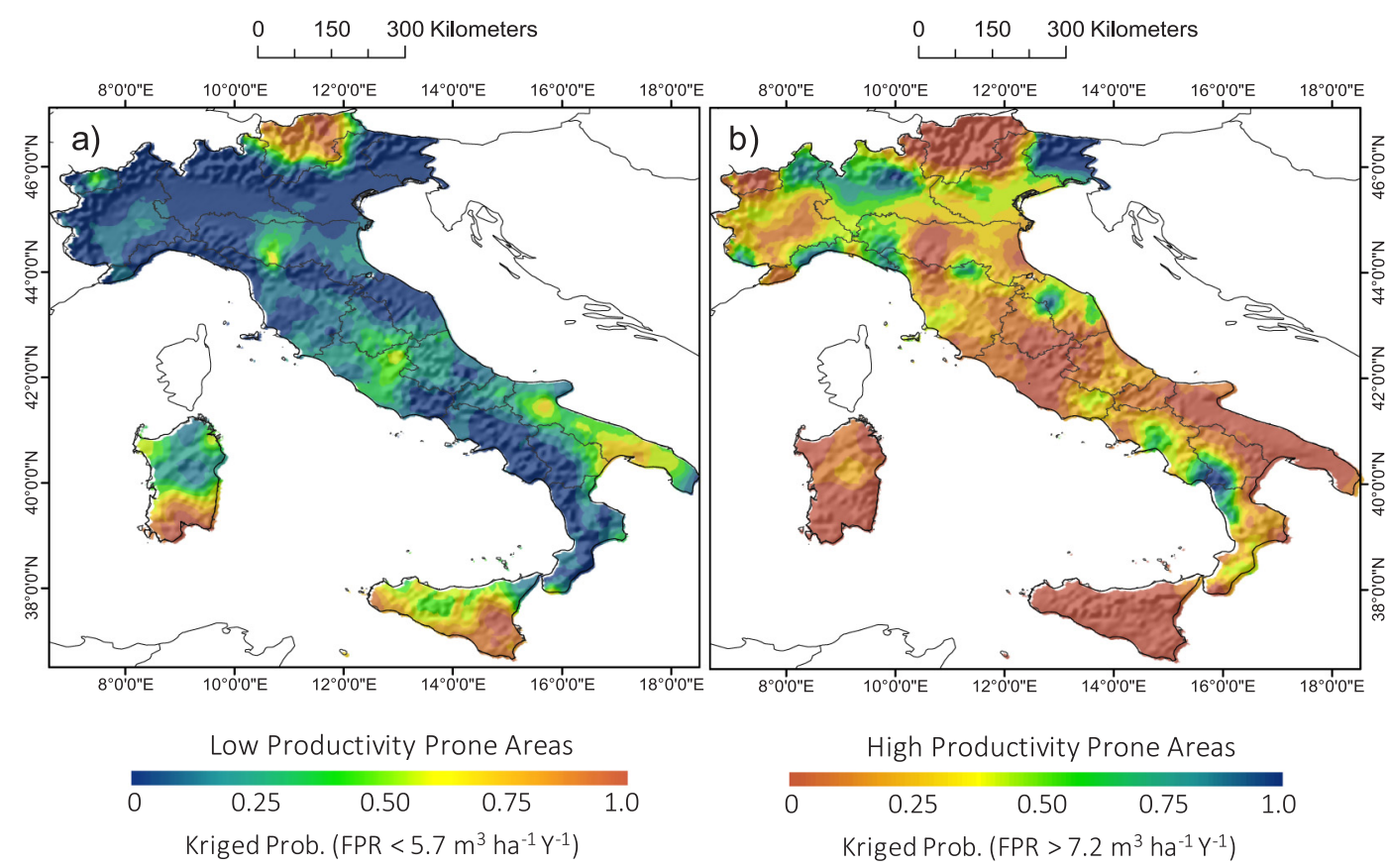

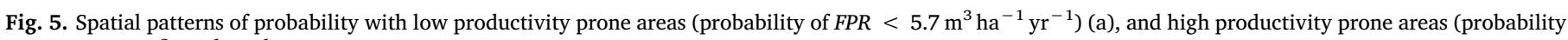
of $F P R>7.2 \mathrm{~m}^{3} \mathrm{ha}^{-1} \mathrm{yr}^{-1}$ ) (b).

in the northwestern part and milder temperatures at lower latitudes (Pfister et al., 2018). In the application of kriging-type analyses, a gradient could mask the stochastic variability in the range of kriging estimates. Kriging with a trend model (detrended kriging) considers that the local mean varies within the local neighbourhood. The local trend can be, for example, a linear relationship between the investigated variable and auxiliary variables. Detrending the data locally (by subtracting a constant value or a best-fit line from data) was thus a part of the prediction process to satisfy stationary assumptions (e.g. Negreiros et al., 2010). Here, a constant detrending with a local neighbourhood was applied (Fig. 3a) as a practical approximation, while straight line or polynomial detrending are applicable to more complex situations requiring strong assumptions about parameter estimation (e.g. Myers, 1994). The data resource was decomposed into a deterministic trend component (which usually changes gradually through space) and an autocorrelated random component (which tends to change more quickly). We assumed that observations on any given year show local variations owing to topography, ground cover and other local factors that are not easily predictable. According to the procedure shown in Goovaerts (1997), once the trend was removed, kriging was carried out on the residuals and the trend was added back to the output surface. The results so obtained indicated that probabilities of high and low productivity are distributed without any apparent latitudinal/longitudinal or altitudinal gradient. While suggesting the possibility of using geostatistical spatial modelling to determine FPR values, the present study also showed limitations. These findings are purely geostatistical, with no explicit mechanistic basis related to forest productivity. However, mechanistic modelling of forest growth is data demanding and state-of-the-art model estimates can be accompanied by a large amount of uncertainties (e.g. Charney et al., 2016). There are also two major criticisms against the Paterson index, that is: (i) it estimates growth potential in terms of timber volume, for which it was originally designed (Johnston et al., 1967; Hagglund, 1981), without providing dry matter biomass, and (ii) it does not consider any soil factor. Some other limitations are in the use of preestablished topo-climatic inputs, which do not include surface insolation, second-order constraints provided by slope and orientation of the local terrain, and soil water regime (e.g. Rahman and Akter, 2015). This approach also overlooks the influence of short-term weather events (and year-to-year variability) on estimated productivity. Relying on credible information regarding forest productivity and its environmental drivers, this study shows how geostatistics methods can be practically implemented to create countrywide spatially explicit probabilistic maps, which could be of direct use for forest management.
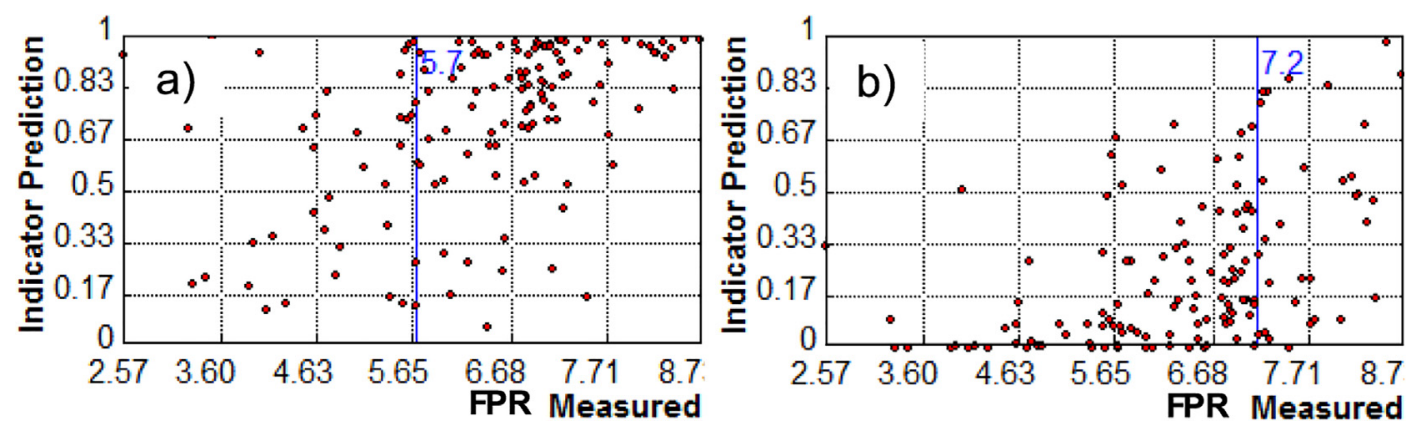

Fig. 6. Scatterplot of cross-validation between the actual forest productivity rate (FPR) and kriged indicator for two thresholds (blue vertical lines): $F P R<5.7 \mathrm{~m}^{3} \mathrm{ha}^{-1} \mathrm{yr}^{-1}$ (a) and FPR $>7.2 \mathrm{~m}^{3} \mathrm{ha}^{-1} \mathrm{yr}^{-1}$ (b). 


\section{Acknowledgement}

This study is an investigator-driven study, which means generation of the study hypothesis, study design, data collection, analysis and interpretation, decision to publish and the preparation of the manuscript were performed without any financial support.

\section{References}

Acquaotta, F., Fratianni, S., Venema, V., 2016. Assessment of parallel precipitation measurements networks in Piedmont, Italy. Int. J. Climatol. 12, 3963-3974. https:// doi.org/10.1002/joc.4606.

Babst, F., Poulter, B., Trouet, V., Tan, K., Neuwirth, B., Wilson, R., Carrer, M., Grabner, M., Tegel, W., Levanic, T., Panayotov, M., Urbinati, C., Bouriaud, O., Ciais, P., Frank, D., 2013. Site- and species-specific responses of forest growth to climate across the European continent. Glob. Ecol. Biogeogr. 22, 706-717. https://doi.org/10.1111/ geb.12023.

Benavides, R., Roig, S., Osoro, K., 2009. Potential productivity of forested areas based on a biophysical model. A case study of a mountainous region in northern Spain. Ann. For. Sci. 66, 108. https://doi.org/10.1051/forest/2008080.

Bohn, U., Hettwer, C., Gollub, G., 2005. Anwendung und Auswertung der Karte der natürlichen Vegetation Europas (Application and analysis of the map of the natural vegetation of Europe). Bundesamt für Naturschutz, BfN-Skripten, Bonn.

Bontemps, J.-D., Bouriaud, O., 2014. Predictive approaches to forest site productivity: recent trends, challenges and future perspectives. Forestry 87 (1).

Box, G.E.P., Cox, D.R., 1964. An analysis of transformations. J. R. Stat Soc. B 26, 211-252.

Burrough, P.A., McDonnell, R.A., 1998. Principles of Geographical Information Systems. Oxford University Press, New York.

Busch, G., 2012. GIS-based tool for regional assessments and planning processes regarding potential environmental effects of poplar SRC. BioEnergy Res. 5, 584-605. https://doi.org/10.1007/s12155-012-9224-0.

Calvert, K., Pearce, J.M., Mabee, W.E., 2013. Toward renewable energy geo-information infrastructures: applications of GIScience and remote sensing that build institutional capacity. Renew. Sustain. Energy Rev. 18, 416-429. https://doi.org/10.1016/j.rser. 2012.10.024.

Charney, N.D., Babst, F., Poulter, B., Record, S., Trouet, V.M., Frank, D., Enquist, B.J., Evans, M.E.K., 2016. Observed forest sensitivity to climate implies large changes in $21^{\text {st }}$ century North American forest growth. Ecol. Lett. 19, 1119-1128. https://doi. org $/ 10.1111 /$ ele.12650.

Churkina, G., Running, S.W., 1998. Contrasting climatic controls on the estimated productivity of global terrestrial biomes. Ecosystems 1, 206-215. https://doi.org/10. 1007/s100219900016.

Combourieu-Nebout, N., Bertini, A., Russo-Ermolli, E., Peyron, O., Klotz, S., Montade, V., Fauquette, S., Allen, J., Fusco, F., Goring, S., Huntley, B., Joannin, S., Lebreton, V. Magri, D., Martinetto, E., Orain, R., Sadori, L., 2015. Climate changes in the central Mediterranean and Italian vegetation dynamics since the Pliocene. Rev. Palaeobotany Palynol. 218, 127-147.

Coops, N.C., 2015. Characterizing forest growth and productivity using remotely sensed data. Curr. For. Rep. 1, 195-205. https://doi.org/10.1007/s40725-015-0020-x.

De Martonne, E., 1926. Aréisme et indice d'aridite. Comptes Rendus de L'Académie des Sciences 182, 1395-1398. (in French).

Diodato, N., Bellocchi, G., 2008b. Modelling NDVI responses to climate variability in Mediterranean terrestrial ecosystem. Environ. Monit. Assess. 44, 147-159. https:// doi.org/10.1007/s10661-007-9964-z.

Diodato, N., Bellocchi, G., 2008a. Drought stress patterns in Italy using agro-climatic indicators. Clim. Res. 36, 53-63. https://doi.org/10.3354/cr00726.

Diodato, N., Bosco, G., 2014. Spatial pattern probabilities exceeding critical threshold of annual mean storm-erosivity in Euro-Mediterranean areas. In: Diodato, N., Bellocchi, G. (Eds.), Storminess and Environmental Change. Springer, Dordrecht, pp. 79-99.

Diodato, N., Ceccarelli, M., 2004. Multivariate indicator Kriging approach using a GIS to classify soil degradation for Mediterranean agricultural lands. Ecol. Indic. 4 , 177-187. https://doi.org/10.1016/j.ecolind.2004.03.002.

Diodato, N., Ceccarelli, M., Bellocchi, G., 2010. GIS-aided evaluation of evapotranspiration at multiple spatial and temporal climate patterns using geoindicators. Ecol. Indic. 10, 1009-1016. https://doi.org/10.1016/j.ecolind.2010.02.009.

Diodato, N., Esposito, L., Bellocchi, G., Vernacchia, L., Fiorillo, F., Guadagno, F.M., 2013. Assessment of the spatial uncertainty of nitrates in the aquifers of the Campania Plain (Italy). Am. J. Clim. Change 2, 128-137. https://doi.org/10.4236/ajcc.2013.22013.

Diodato, N., Soriano, M., Bellocchi, G., Fiorillo, F., Cevasco, A., Revellino, P., Guadagno, F.M., 2017. Historical evolution of slope instability in the Calore River Basin, Southern Italy. Geomorphology 282, 74-84. https://doi.org/10.1016/j.geomorph. 2017.01.010.

FAO, 2014. Web LocClim: Local Monthly Climate Estimator. http://www.fao.org/nr/ climpag/locclim/locclim en.asp.

Forzieri, G., Alkama, R., Miralles, D.G., Cescatti, A., 2017. Satellites reveal contrasting responses of regional climate to the widespread greening of Earth. Science 356, 1180-1184. https://doi.org/10.1126/science.aal1727.

Gaillard, M.J., Morrison, K.D., Madella, M., Whitehouse, N., 2018. Past land-use and landcover change: the challenge of qualification at the subcontinental to global scales. Past Glob. Change Magazine 26, 1-44. https://doi.org/10.22498/pages.26.1.

Gandullo, J.M., Serrada, R., 1977. Mapa de productividad potencial forestal de la España peninsular. Instituto Nacional de Investigación y Tecnología Agraria y Alimentaria, Madrid (in Spanish).
Gasparini, P., Di Cosmo, L., Rizzo, M., Giuliani, D., 2017. A stand-level model derived from National Forest Inventory data to predict periodic annual volume increment of forests in Italy. J. Forest Res. 22, 209-217. https://doi.org/10.1080/13416979.2017. 1337260.

Goovaerts, P., 1997. Geostatistics for Natural Resources Evaluation. Oxford University Press, New York.

Goreaud, F., Courbaud, B., Collinet, F., 1999. Spatial structure analysis applied to modelling of forest dynamics: a few examples. Oeiras In: Amaro, A., Tomé, M. (Eds.), Proceedings of the IUFRO Workshop, Empirical and Process Based Models for Forest Tree and Stand Growth Simulation, pp. 155-172.

Hörsch, B., 2003. Modelling the spatial distribution of montane and subalpine forests in the central Alps using digital elevation models. Ecol. Model. 168, 267-282. https:/ doi.org/10.1016/S0304-3800(03)00141-8.

Isaaks, E.H., Srivastava, R.M., 1989. An Introduction to Applied Geostatistics. Oxford University Press, New York.

Johnston, D.R., Grayson, A.J., Bradley, R.T., 1967. Forest planning. Faber and Faber Limited, London.

Johnston, K., Ver Hoef, J.M., Krivoruchko, K., Lucas, N., 2001. Using ArcGis geostatistical analyst. ESRI, Redlands.

Journel, A.G., Huijbregts, C.H., 1978. Mining Geostatistics. Academic Press, New York.

Kim, M., Lee, W.-K., Son, Y., Yoo, S., Choi, G.-M., Chung, D.-J., 2017. Assessing the impacts of topographic and climatic factors on radial growth of major forest forming tree species of South Korea. For. Ecol. Manage. 404, 269-279. https://doi.org/10. 1016/j.foreco.2017.08.048.

Kitanidis, P.K., 1997. Introduction to Geostatistics: Application to Hydrogeology. Cambridge University Press, Cambridge.

Knotters, M., Brus, D.J., Oude Voshaar, J.H., 1995. A comparison of kriging, co-kriging and kriging combined with regression for spatial interpolation of horizon depth with censored observations. Geoderma 67, 227-246. https://doi.org/10.1016/00167061(95)00011-C

Laurin, G.V., Balling, J., Corona, P., Mattioli, W., Papale, D., Puletti, N., Rizzo, M., Truckenbrodt, J., Urban, M., 2018. Above-ground biomass prediction by Sentinel-1 multitemporal data in central Italy with integration of ALOS2 and Sentinel-2 data. J. Appl. Remote Sens. 12, 016008. https://doi.org/10.1117/1.JRS.12.016008.

Lindner, M., Maroschek, M., Netherer, S., Kremer, A., Barbati, A., Garcia-Gonzalo, J., Seidl, R., Delzon, S., Corona, P., Kolström, M., Lexer, M.J., Marchetti, M., 2010. Climate change impacts, adaptive capacity, and vulnerability of European fores ecosystems. For. Ecol. Manage. 259, 698-709. https://doi.org/10.1016/j.foreco. 2009.09.023.

Lionello, P., Malanotte-Rizzoli, P., Boscolo, R., 2006. Mediterranean Climate Variability. Elsevier, Amsterdam.

Martinez del Castillo, E., Tejedor, E., Serrano-Notivoli, R., Novak, K., Saz, M.A., Longares, L.A., de Luis, M., 2018. Contrasting patterns of tree growth of Mediterranean pine species in the Iberian peninsula. Forests 9, 416. https://doi.org/10.3390/f9070416.

Maselli, F., Barbati, A., Chiesi, M., Chirici, G., Corona, P., 2006. Use of remotely sensed and ancillary data for estimating forest gross primary productivity in Italy. Remote Sens. Environ. 100, 563-575. https://doi.org/10.1016/j.rse.2005.11.010.

Morin, X., Fahse, L., Jactel, H., Scherer-Lorenzen, M., García-Valdés, R., Bugmann, H., 2018. Long-term response of forest productivity to climate change is mostly driven by change in tree species composition. Sci. Rep. 8, 5627. https://doi.org/10.1038/ s41598-018-23763-y.

Myers, D.E., 1994. Statistical methods for interpolation of spatial data. Int. J. Appl. Sci. Comput. 1, 283-318.

Næsset, 1997. Geographical information systems in long-term forest management and planning with special reference to preservation of biological diversity: a review. For. Ecol. Manage. 93, 121-136. https://doi.org/10.1016/S0378-1127(96)03928-X.

Negreiros, J., Painho, M., Aguilar, F., Aguilar, M., 2010. Geographical information systems principles of ordinary kriging interpolator. J. Appl. Sci. 10, 852-867. https:// doi.org/10.3923/jas.2010.852.867.

Ollinger, S.V., Aber, J.D., Federer, C.A., 1998. Estimating regional forest productivity and water yield using an ecosystem model linked to a GIS. Landscape Ecol. 13, 323-334. https://doi.org/10.1023/A:1008004423783.

Paterson, S.S., 1956. The Forest Area of the World and its Potential Productivity. Royal University of Göteborg, Department of Geography, Göteborg.

Payn, T.W., Hill, R.B., Höck, B.K., Skinner, M.F., Thorn, A.J., Rijkse, W.C., 1999. Potential for the use of GIS and spatial analysis techniques as tools for monitoring changes in forest productivity and nutrition, a New Zealand example. For. Ecol. Manage. 122, 187-196. https://doi.org/10.1016/S0378-1127(99)00041-9.

Pfister, C., Brázdil, R., Luterbacher, J., Ogilvie, A.E.J., White, S., 2018. Early modern Europe. In: White, S., Pfister, C., Mauelshagen, F. (Eds.), The Palgrave Handbook of Climatehistory. Palgrave Macmillan, London, pp. 265-295.

Pignatti, G., De Natale, F., Gasparini, P., Mariano, A., Trisorio, A., 2012. High Nature Value forest areas: a proposal for Italy based on national forest inventory data. L'Italia Forestale e Montana 67, 281-288. https://doi.org/10.4129/ifm.2012.3.06.

Purves, D., Pacala, S., 2008. Predictive models of forest dynamics. Science 320 , 1452-1453. https://doi.org/10.1126/science.1155359.

Qiu, B.W., Zhong, M., Tang, Z.H., Chen, C.C., 2013. Spatiotemporal variability of vegetation phenology with reference to altitude and climate in the subtropical mountain and hill region, China. Chin. Sci. Bull. 58, 2883-2892. https://doi.org/10.1007/ s11434-013-5847-6.

Rahman, Md.S., Akter, S., 2015. Climate to forest productivity: implication of Paterson's CVP Index. Res. J. For. 9, 27-34. https://doi.org/10.3923/rjf.2015.27.34.

Rahman, Md.S., Akter, S., Al-Amin, M., 2015. Forest and agro-ecosystem productivity in Bangladesh: a climate vegetation productivity approach. Forest Sci. Technol. 11, 126-132. https://doi.org/10.1080/21580103.2014.957358.

Serrada, R., 1976. Método para la evaluación con base ecológica de la productividad 
potencial de las masas forestales en grandes regiones y su aplicación en la España Peninsular, Ph.D. thesis, unpublished, Universidad Politécnica de Madrid, Madrid (in Spanish).

Stegen, J.C., Swenson, N.G., Enquist, B.J., White, E.P., Phillips, O.L., Jørgensen, P.M., Weiser, M.D., Monteagudo Mendoza, A., Núñez Vargas, P., 2011. Variation in aboveground forest biomass across broad climatic gradients. Glob. Ecol. Biogeogr 20, 744-754. https://doi.org/10.1111/j.1466-8238.2010.00645.x.

Thiffault, E., Barrette, J., Paré, D., Titus, B.D., Keys, K., Morris, D.M., Hope, G., 2014. Developing and validating indicators of site suitability for forest harvesting residue removal. Ecol. Indic. 43, 1-18. https://doi.org/10.1016/j.ecolind.2014.02.005.
Tobler, W.R., 1970. A computer movie simulating urban growth in the Detroit region. Econ. Geogr. 46, 234-240. https://doi.org/10.2307/143141.

Voronoi, G., 1908. Nouvelles applications des paramètres continus à la théorie des formes quadratiques. Journal für die Reine und Angewandte Mathematik 133, 97-178. https://doi.org/10.1515/crll.1908.133.97. (in French).

Wang, J., Hall, C.A.S., Scantena, F.N., Fetcher, N., Wu, W., 2003. Modeling the spatial and temporal variability in climate and primary productivity across the Luquillo Mountains, Puerto Rico. For. Ecol. Manage. 179, 69-94. https://doi.org/10.1016/ S0378-1127(02)00489-9. 